\title{
Young Australian adults' knowledge and beliefs about organ donation
}

\begin{abstract}
Context-Limited studies, particularly in Australia, are aimed at understanding young people's beliefs about organ donation. Identification of such beliefs may serve to increase donation decision registration and decision discussion rates among this age cohort.

Objectives-To examine young adults' knowledge about organ donation and to use a theory of planned behavior framework to determine the differences in behavioral, normative, and control beliefs between young adults who had and those who had not registered and discussed their organ donation decision with family or significant others.

Participants - Australian university students $(\mathrm{N}=233$ ) completed a questionnaire assessing knowledge about the organ donation process and beliefs related to organ donation decision registration and decision discussion.

Results-Young adults demonstrated knowledge deficits about the support of Westem religious denominations for organ donation and the circumstances surrounding donation. Unregistered donors were more likely to focus on the costs of registering; however, no belief-based differences for decision discussion emerged. Young adults who had registered and discussed their decision were more likely to believe that family members and friends thought they should do so. Lack of motivation was reported as preventing registering and discussing, and uncertainty about how and when to raise the topic prevented young adults discussing their donation decision. Conclusions-Understanding of young adults' knowledge and beliefs enables the development of strategies encouraging donation decision registration and donation decision discussion with family or significant others, thereby increasing the likelihood that the donor's wishes will be carried out. (Progress in Transplantation. 2007;17:220-227)
\end{abstract}

\author{
Mellssa K. Hyde, BPsych \\ (Hons), \\ Katherine M. White, PhD \\ Queensland University of Technology, \\ Brisbane, Australia
}

To purchase electronic or print reprints, contact:

The InnoVision Group

101 Columbia, Aliso Viejo, CA 92656

Phone (800) 809-2273 (ext 532) or

(949) 448-7370 (ext 532)

Fax (949) 362-2049

E-mail reprints@aacn.org

\begin{abstract}
$\mathrm{L}$ ittle research has examined the factors influencing Lyoung people's organ donation decisions,' particularly in Australia, which has one of the lowest organ donation rates in the world ( 10 donors per million population) relative to other countries with opt-in systems such as the United States (21.4 donors per million population) ${ }^{24}$ The organ donation-related behaviors of young Australians, such as registering and discussing their organ donation preference with family or significant others, are particularly important to study because communication of the donation decision increases the likelihood that the donor's wishes will be enacted. It is essential for individuals wishing to donate to discuss their decision with their partner and/or family members given the low family consent rate in Australia (50\%) ${ }^{5}$ and to consult with family to give authority for organ donation. ${ }^{3}$

In Australia, even if an individual has registered his or her intent or consent to donate, family members
\end{abstract}

are still consulted to confirm the donation decision, and, in cases in which an individual's decision is unknown, authority for organ donation will be sought from family members. ${ }^{36}$ In addition, previous research indicates that young people are more likely than older people to donate' and are more likely to have the opportunity to donate their organs as they tend to engage in high-risk behaviors. ${ }^{3}$ These outcomes suggest that to increase organ donation decision registration and decision discussion, a focus on the factors influencing young people's organ donation decisions is warranted.

Research from other Westernized countries has indicated that knowledge, beliefs, attitudes, and norms influence whether young people register or discuss their donation decision with family or significant others. ${ }^{8.9}$ Lack of knowledge about organ donation is often reported as a barrier to registering and discussing the donation decision. ${ }^{10}$ These knowledge deficits 
include the belief that most Western religious groups do not support the concept of organ donation, confusion about the concept of brain death, and uncertainty about the particular organs and tissues able to be donated upon death. ${ }^{11.12}$

An individual's positive and negative beliefs and attitudes have also been shown to contribute to organ donation-related decisions. Negative beliefs and attitudes preventing donation decision registration include fear of being declared dead prematurely for the purpose of extracting organs and fear of mutilation and the body not being whole after death. ${ }^{7.13 .14}$ Beliefs preventing decision discussion include appearing ignorant, being uncertain about the donation decision, and having to defend or justify the donation decision. ${ }^{15}$ Religious beliefs and affiliation are also reported as reasons preventing decision registration and discussion. ${ }^{10}$

Positive beliefs and attitudes encouraging the donation of organs upon death are mainly altruistic and include helping others, saving another person's life, and improving the quality of another person's life..$^{10.11}$ Finally, reported normative beliefs influencing donation-related decisions include the belief that significant others would support or object to the individual's donation decision. ${ }^{10}$

Despite the contribution of beliefs to organ donation decisions, there is little research examining the beliefs affecting the registration and discussion decisions of young Australians. A useful theoretical framework allowing examination of such beliefs is the theory of planned behavior (TPB). ${ }^{16}$ According to the TPB, intentions are the most proximal determinant of behavior. Intentions are influenced by 3 constructs: attitudes (positive or negative evaluation of the behavior), subjective norm (perceptions of important others regarding behavioral performance), and perceived behavioral control (perceived control over behavioral performance). ${ }^{16,17}$ In addition, the TPB proposes that the constructs of attitude, subjective norm, and perceived behavioral control are determined by underlying behavioral (costs and benefits), normative (pressure to comply with important others), and control beliefs (motivating or inhibiting factors), respectively. ${ }^{16} \mathrm{~A}$ major advantage of the TPB is its ability to identify the underlying behavioral, normative, and control beliefs that distinguish those performing and not performing the behavior under investigation. A number of studies have conducted belief-based analyses using the TPB framework to understand health behaviors, including blood donation ${ }^{18}$ and binge-drinking. ${ }^{19}$

Use of TPB belief-based analyses to understand the beliefs influencing young Australians' organ donation decisions will enable the development of targeted strategies to increase decision registration and discussion rates. Thus, in addition to examining young adults' general knowledge about the organ donation process, we aimed to investigate whether young adults who have and have not (1) registered their donation decision and (2) discussed their donation decision with family differ according to their behavioral, normative, and control beliefs about registering and discussing the donation decision.

\section{Methods \\ Participants}

Participants were university students enrolled in an introductory psychology unit who were recruited via university notice boards, in-class announcements, and notices posted on online teaching sites and who volunteered to participate in the study. The sample comprised 233 (180 women, 52 men, 1 unspecified) primarily white (83\%), Australian students aged 17 to 25 years (mean $[S D]=19.8[2.2]$ years). The remaining $17 \%$ of the sample who reported that they were not white were classified on the basis of the Australian Standard Classification of Countries ${ }^{20}$ as North-East Asian $(n=19)$, South East Asian $(n=4)$, Southern Asian $(n=4)$, Middle Eastern $(n=3)$, Southern European $(n=1)$, Central American $(n=1)$, Indigenous Australian $(n=1)$, and Maori $(n=1) ; 4$ participants did not give a response about their ethnicity.

Most participants reported identifying with a formal religion (70\%). More than half $(59 \%)$ of the participants had registered either intent or consent to donate. Few participants knew someone who was an organ donor (13\%), a transplant recipient $(24 \%)$, or on a transplant waiting list (9\%). Participants completed a questionnaire assessing the belief-based TPB measures (as specified by Ajzen ${ }^{16}$ ) related to (1) registering the decision to donate organs upon death and (2) discussing the donation decision with family members or significant others. Most students received research participation credit for their involvement.

\section{Measures}

The target behaviors were registering the donation decision and discussing the donation decision with family or significant others. Registering the decision to donate or not donate organs upon death (registering) was defined as "Having recorded your intent/consent to donate some or all of your organs and/or tissue upon your death, for transplantation." Recent changes introduced by the Australian government to increase organ donation rates have resulted in a situation in which Australians who had previously registered their intent to donate upon death are required to reregister their legally valid consent or objection on the Australian Organ Donor Register. ${ }^{21}$ To account for the changeover and given that there was some degree of confusion about appropriate methods to register at the time this study was conducted, we considered participants who had registered intent or consent by any method to be 
Table 1 Questions used to ascertain participants' knowledge of the donation process (true/false answers) and percentage of participants who answered the questions correctly

\begin{tabular}{|c|c|c|}
\hline Questions & $\begin{array}{l}\text { Correct } \\
\text { response }\end{array}$ & $\begin{array}{c}\% \\
\text { correct }\end{array}$ \\
\hline $\begin{array}{l}\text { 1. Only persons aged } 18 \text { years or older can register their consent or objection on the Australian Organ } \\
\text { Donor Register. }\end{array}$ & True & 60 \\
\hline 2. There are almost 2000 people in Australia on organ transplant waiting lists at any given time. & True & 90 \\
\hline 3. Almost all western religious groups support the concept of organ/tissue donation. & True & 35 \\
\hline $\begin{array}{l}\text { 4. In most cases, organs can only be donated if a person has died in an intensive care unit under special } \\
\text { circumstances (eg, brain death). }\end{array}$ & True & 44 \\
\hline 5. Once registered on the Australian Organ Donor Register, your consent cannot be revoked. & False & 92 \\
\hline $\begin{array}{l}\text { 6. Before a donors' organs can be removed a physician must certify that the potential donors' heart has } \\
\text { ceased to function and that all pulmonary activity has ceased. }\end{array}$ & False & 13 \\
\hline $\begin{array}{l}\text { 7. The Australian Organ Donor Register is the only national register for organ and tissue donation for } \\
\text { transplantation. }\end{array}$ & True & 82 \\
\hline 8. A greater number of people have the opportunity to donate tissue for transplantation. & True & 76 \\
\hline 9. The donors' family are responsible for the hospital and surgery costs for removing and transplanting organs. & False & 91 \\
\hline 10. The potential donors have complete choice over which organs and tissue they are prepared to donate. & True & 82 \\
\hline 11. Anyone over the age of $\mathbf{4 0}$ is not acceptable as an organ donor. & False & 92 \\
\hline $\begin{array}{l}\text { 12. Brain death occurs when there is irreversible cessation of all functions of the entire brain including the } \\
\text { brain stem. }\end{array}$ & True & 91 \\
\hline 13. The donation of organs and tissue does not alter the physical appearance of the body. & True & 60 \\
\hline 14. The ideal donor is a young adult who has died of a head injury. & True & 60 \\
\hline $\begin{array}{l}\text { 15. It is important to discuss your donation decision with your family/partner/close friend, as they may be } \\
\text { asked to confirm that you have or have not changed your mind since recording your consent. }\end{array}$ & True & 97 \\
\hline 16. The process of organ donation results in a significant delay in normal funeral arrangemen & False & 81 \\
\hline
\end{tabular}

a Please note that unlike other countries where donation after cardiac death is a relatively common practice, non-heart-beating donation rarely occurs in Australia, where virtually all organ donations occur in the setting of brain death.

classified as registered for the purposes of the study. Discussing the donation decision to donate or not donate organs upon death (discussing) was defined as "Having talked to your family, partner, or close friend about your donation decision."

\section{Elicitation Study}

According to guidelines specified by Ajzen, ${ }^{16}$ it is important to obtain an accurate representation of the beliefs about the target behavior that are relevant specifically to the population of interest before the formation of the questionnaire for the larger study. Thus, an elicitation study was conducted with 14 introductory psychology students to identify the salient behavioral, normative, and control beliefs for the 2 organ donation-related behaviors. The most commonly occurring behavioral, normative, and control beliefs formed the belief-based items in the main questionnaire. ${ }^{16}$ Sample characteristics were largely representative of those from the main study.

\section{Main Questionnaire}

The main questionnaire assessed general knowledge about the organ donation process and measured behavioral, normative, and control beliefs for the 2 behaviors of registering and discussing. Most belief items were positively worded with some negatively worded items included to reduce participant response bias.

Knowledge. Participants' perceived and actual knowledge of the organ donation process were measured. Respondents self-rated their knowledge of organ and tissue donation for transplantation purposes $(1=$ very poor to $7=$ excellent). Participants then indicated which of 12 organs/tissue listed they believed could be donated, and responded to 16 factual statements regarding organ/tissue donation or the act of becoming an organ/tissue donor (true or false). The 16 true/false items (Table 1) were based broadly on Horton and Horton ${ }^{12}$ and were adapted from the frequently asked questions in the Australian Organ Donor Register brochure. ${ }^{22}$ Responses to factual knowledge items were scored as 0 incorrect or 1 correct.

Beliefs. All belief items were rated on scales from 1 (extremely unlikely) to 7 (extremely likely); the results are presented in Tables 2 and 3. For behavioral 
Table 2 Mean differences in beliefs about organ donation of registered and unregistered young adults

\begin{tabular}{|c|c|c|}
\hline Beliefs & $\begin{array}{l}\text { Not registered } \\
\quad(n=94)\end{array}$ & $\begin{array}{c}\text { Registered } \\
(n=137)\end{array}$ \\
\hline \multicolumn{3}{|l|}{ Behavioral } \\
\hline $\begin{array}{l}\text { Saving or improving the lives of other people } \\
\text { Being unsure attempts would be made to save my life } \\
\text { Saving others from having to make the decision for me } \\
\text { Removing organs means my body isn't whole after death } \\
\text { Creating distress for loved ones if they disagree with my decision } \\
\text { Avoiding the waste of healthy organs and/or tissues } \\
\text { Enable efficient procedures to assist in the donation process } \\
\text { Being unable to change my mind if I die prematurely }\end{array}$ & $\begin{array}{l}6.20 \\
3.81 \\
5.09 \\
4.68 \\
4.90 \\
5.17 \\
4.94 \\
4.40\end{array}$ & $\begin{array}{l}6.22 \\
2.73^{\mathrm{a}} \\
5.58 \\
3.30^{\mathrm{a}} \\
3.34^{\mathrm{a}} \\
5.86^{\mathrm{b}} \\
5.84^{\mathrm{a}} \\
3.47^{\mathrm{a}}\end{array}$ \\
\hline $\begin{array}{l}\text { Normative } \\
\text { Partner/family members } \\
\text { Friends } \\
\text { Doctors and other medical professionals } \\
\text { Potential organ and/or tissue transplant recipients } \\
\text { Church and religious group members }\end{array}$ & $\begin{array}{c}(n=95) \\
4.03 \\
4.49 \\
5.67 \\
6.28 \\
3.61\end{array}$ & $\begin{array}{l}5.87^{\mathrm{a}} \\
5.58^{\mathrm{a}} \\
6.30^{\mathrm{a}} \\
6.69^{\mathrm{b}} \\
4.24^{\mathrm{b}}\end{array}$ \\
\hline $\begin{array}{l}\text { Control } \\
\text { Lack of knowledge about how to register } \\
\text { Lack of motivation to register } \\
\text { Lack of knowledge about the donation process in general } \\
\text { Adherence to religious principles }\end{array}$ & $\begin{array}{c}(n=95) \\
3.72 \\
4.19 \\
4.74 \\
2.76\end{array}$ & $\begin{array}{l}3.65 \\
3.23^{\mathrm{a}} \\
3.96^{\mathrm{b}} \\
2.22\end{array}$ \\
\hline $\begin{array}{l}\mathrm{a} P<.001 . \\
\mathrm{b} P<.006 .\end{array}$ & & \\
\hline
\end{tabular}

beliefs, participants rated how likely 4 costs (eg, being unable to change my mind if I die prematurely) and 4 benefits (eg, saving or improving the lives of others) were to occur if they registered. Participants also rated the likelihood that 3 costs (eg, feeling pressure to change my mind) and 3 benefits (eg, making those who are close to me aware of my decision) would occur if they discussed their decision. The measures of normative beliefs required participants to rate the likelihood that 5 specific referents (eg, family members) would approve of them registering and discussing. For control beliefs, respondents rated the likelihood that 4 factors (eg, lack of motivation) would prevent them from registering and discussing. According to TPB guidelines, ${ }^{16}$ it is not expected that the belief-based scales will be internally consistent given that an individual's endorsement of specific beliefs about a given behavior is likely to contain a degree of ambivalence because some beliefs are valued positively and other beliefs are valued negatively. As a result, there is no expectation that beliefs will correlate highly with each other.

\section{Results}

Correlational analysis was initially conducted to confirm that registering and discussing were considered to be separate behaviors by participants and, therefore, warranted separate analyses. Although these behaviors may be strongly related to each other for some individuals, they were correlated at only $r=$
.21 in our study, suggesting that they are largely distinct behaviors for the present sample.

\section{Knowledge}

Participants' self-ratings of knowledge indicated they had a slightly below average level of knowledge (mean $[\mathrm{SD}]=3.5[1.3]$ ), evidenced by ratings of their knowledge as poor or very poor $(25 \%)$ to average $(59 \%)$. Only a small percentage of young adults indicated they had a good to excellent level of knowledge about the topic of organ donation (16\%). Responses to the questions regarding which organs/tissues can be donated revealed that almost all participants reported correctly that the kidneys $(99 \%)$, heart $(95 \%)$, and liver $(93 \%)$ could be donated. The majority of participants were aware that the lungs $(82 \%)$ and bone tissue $(71 \%)$ could be donated; however, there was some confusion about donation of skin tissue $(55 \%)$, heart valves $(62 \%)$, corneas $(52 \%)$, and the pancreas $(65 \%)$. Responses to the 16 factual statements indicated that the average knowledge score for registered participants was 11.53 and 11.30 for unregistered participants (of 16 possible correct responses). There was no significant difference in knowledge levels between participants who had and those who had not registered $\left(\mathrm{F}_{1,228}=1.08, P=.301\right)$.

As shown in Table 1, responses to the 16 factual statements indicated that most participants responded to 3 questions incorrectly about the support of western religious groups for the concept of organ donation and 
Table 3 Mean differences in beliefs about organ donation of young adults having discussed and not discussed their decision

\begin{tabular}{|c|c|c|}
\hline Beliefs & $\begin{array}{l}\text { Not discussed } \\
\quad(n=62)\end{array}$ & $\begin{array}{c}\text { Discussed } \\
(n=170)\end{array}$ \\
\hline \multicolumn{3}{|l|}{ Behavioral } \\
\hline $\begin{array}{l}\text { Making those who are close to me aware of my decision } \\
\text { Creating conflict among those who are close to me } \\
\text { Gaining approval from those who are close to me } \\
\text { Feeling pressure to change my mind } \\
\text { Being aware of the donation decision of those close to me } \\
\text { Feeling uncomfortable talking about death-related topics }\end{array}$ & $\begin{array}{l}6.08 \\
3.05 \\
4.95 \\
3.32 \\
5.23 \\
3.31\end{array}$ & $\begin{array}{l}6.19 \\
2.84 \\
5.05 \\
2.82 \\
5.52 \\
2.86\end{array}$ \\
\hline \multicolumn{3}{|l|}{ Normative } \\
\hline $\begin{array}{l}\text { Partner/family members } \\
\text { Friends } \\
\text { Doctors and other medical professionals } \\
\text { Potential organ and/or tissue transplant recipients } \\
\text { Church and religious group members }\end{array}$ & $\begin{array}{l}5.18 \\
4.77 \\
5.82 \\
5.65 \\
4.60\end{array}$ & $\begin{array}{l}6.02^{\mathrm{a}} \\
5.38^{\mathrm{b}} \\
5.81 \\
5.69 \\
4.66\end{array}$ \\
\hline \multicolumn{3}{|l|}{ Control } \\
\hline $\begin{array}{l}\text { Uncertainty about when to raise the topic } \\
\text { Lack of motivation to talk } \\
\text { Uncertainty about how to raise the topic } \\
\text { Adherence to religious principles }\end{array}$ & $\begin{array}{l}3.65 \\
4.42 \\
3.85 \\
1.98\end{array}$ & $\begin{array}{l}2.89^{\mathrm{b}} \\
3.16^{\mathrm{a}} \\
2.84^{\mathrm{a}} \\
1.92\end{array}$ \\
\hline $\begin{array}{l}\text { a } P<.001 \\
b \quad p<.006 .\end{array}$ & & \\
\hline
\end{tabular}

the circumstances surrounding donation. Specifically, $87 \%$ incorrectly believed that before a donor's organs could be removed a physician must certify that the donor's heart had stopped beating-in Australia, non-heart-beating donation is uncommon, with only 9 donations after cardiac death occurring in $2005 .^{3}$ In addition, more than half of the sample $(54 \%)$ were unaware that organ donation can usually only occur if a person has died in an intensive care unit under special circumstances such as brain death.

\section{Beliefs}

A dichotomous independent variable was created to distinguish between young adults who had registered their donation decision and those who had not registered. Participants reporting that they had registered their intent to donate via their driver's license, the donor register, or a donor card were classified as registered donors $(n=137)$, scored as 1 . Those responding that they were undecided or had not registered were classified as unregistered donors $(n=94)$, scored as 0 . In order to distinguish between young adults who had discussed their donation decision and those who had not, a dichotomous independent variable was used. Participants reporting that they had discussed their donation decision with their family, partner, or close friend by responding yes $(n=170)$ were classified as having discussed their decision, scored as 1 . Those responding no $(n=$ 62) were classified as not having discussed their donation decision, scored as $\mathbf{0}$. Overall, responses indicated that the majority of young adults sampled had both registered their intent to donate and had discussed their organ donation decision.

Behavioral, normative, and control beliefs were examined to identify those beliefs differentiating between (1) young adults who had registered their donation decision and those who had not and (2) young adults who had discussed their donation decision and those who had not. Three 1-way multivariate analyses of variance were conducted for each behavior (registering and discussing). For registering, significant Wilks $\lambda$ indicated there were differences in behavioral, normative, and control beliefs between young adults who had registered and those who had not registered their donation decision. For discussing, significant Wilks $\lambda$ indicated there were differences in normative and control beliefs (but not behavioral beliefs) between young adults who had and those who had not discussed their donation decision. In order to further explore the identified differences between the groups, behavioral, normative, and control beliefs were examined at the univariate level with Bonferroni adjustments used to control for familywise type I error (Tables 2 and 3).

Univariate analyses of differences in behavioral, normative, and control beliefs for registering revealed that registered young adults were more likely to believe that avoiding the waste of healthy organs and enabling efficient procedures were benefits of registering the donation decision, compared to unregistered young adults. Unregistered young adults were more likely than registered young adults to question whether lifesaving attempts would be instigated, whether the 
body would be whole after death, whether distress would be created for loved ones, and whether they would be unable to change their mind.

Registered and unregistered young adults did not differ in their belief that saving or improving the lives of others and saving others from having to make the decision for them were benefits of registering. Registered young adults were more likely to believe that all identified referents (eg, partner, family members, friends, physicians and medical professionals, transplant recipients, church/religious group members) would approve of them registering their donation decision compared to unregistered young adults. Finally, unregistered young adults were more likely to perceive lack of motivation to register and lack of knowledge about the donation process in general as barriers to registering the donation decision, compared to registered young adults.

For discussing, univariate analyses of differences in normative and control beliefs (there were no behavioral belief differences) revealed that young adults who had not discussed their donation decision were less likely to believe that their partner or family members and friends would approve of their decision, compared to young adults who had discussed their donation decision. In addition, young adults who had not discussed their donation decision were more likely to perceive uncertainty about when and how to raise the topic and lack of motivation to discuss the donation decision as barriers to discussing compared to young adults who had discussed their donation decision.

\section{Discussion}

This study examined the organ donation-related knowledge and beliefs of young Australian adults in an effort to increase understanding of the factors influencing organ donation decision registration and decision discussion with family and significant others in this age cohort. Results of perceived knowledge ratings revealed that, consistent with other studies, ${ }^{12}$ few young adults reported feeling well informed about the topic of organ donation. Responses to actual knowledge questions indicated that most young adults were aware of which organs can be donated but had less knowledge about tissues (eg, skin tissue and corneas), suggesting a potential area for future intervention.

Consistent with other organ donation knowledge studies, ${ }^{12}$ three main knowledge deficit areas were identified. Specifically, young adults incorrectly believed that most Western religious denominations do not support the concept of organ donation and that the heart of a brain-dead donor has stopped beating when organ removal occurs (although most participants correctly identified the definition of brain death). Over half of the young adults in the sample were also unaware that in most cases, in Australia, organs can only be donated if the donor has died in an intensive care unit under circumstances such as brain death. These incorrect responses suggest that, despite educational efforts, the same knowledge deficits about religious support and the circumstances surrounding organ donation still remain as barriers to decision registration for young adults and should continue to be future targets for intervention. In particular, almost $90 \%$ of the sample believed incorrectly that all pulmonary activity must cease before donation can occur, which suggests that efforts are needed to increase the awareness of young Australian adults that non-heartbeating donation rarely occurs in Australia.

Theory of planned behavior belief-based analyses revealed differences in the beliefs of young adults who had (1) registered and not registered as organ donors and (2) discussed and not discussed their donation decision with family or significant others. Behavioral belief differences were revealed between registered and unregistered young adults regarding both the benefits and costs of registering the donation decision (but not for discussing the decision). Unregistered young adults were more likely to focus on a range of costs of registering the donation decision, including being uncertain that lifesaving attempts would be instigated if they wished to be an organ donor, creating distress for their family if they disagreed with the decision, and being unable to change their mind about being a donor if they were to die prematurely. Unregistered donors were also significantly less likely to consider that 2 of the listed benefits of enabling efficient procedures to assist in the donation process and avoiding the waste of healthy organs would result from registration of the donation decision.

Focusing on decreasing perceptions of the costs of registering as an organ donor (eg, being unable to change the donation decision) and increasing perceptions of some of the benefits of registering (eg, avoiding the waste of healthy organs) may be a potential future strategy to increase registration behavior. Interestingly, young adults did not differ in their belief that saving or improving the lives of others and saving others from having to make the decision for them were benefits of registering. This finding suggests that a focus on such altruistic messages to increase registration rates may not be the best strategy to employ, because young adults are already persuaded by these concepts. The lack of behavioral belief differences between young adults who had and had not discussed their donation decision suggests that it would not be a worthwhile strategy to focus on the costs and benefits of discussing the donation decision as they are perceived similarly by behavioral performers and nonperformers.

Examination of normative beliefs revealed 2 common sources of perceived normative pressure. For both registering and discussing, behavioral performers 
were more likely than nonperformers to believe that their partner or other family members and friends were likely to think that they should register as an organ donor and discuss their decision. Therefore, a possible strategy to encourage registration and discussion of the donation decision is to remind young adults that their friends and family would want them to communicate their donation decision. In addition, registered participants also believed that physicians and medical professionals, transplant recipients, and church/religious group members would approve of them registering their donation decision, suggesting the benefit of involving other potential sources of normative influence to encourage registration behavior for unregistered young adults.

For control beliefs, a consistent factor preventing young adults from registering and discussing behavior was lack of motivation. A useful strategy to increase motivation may be to emphasize how easy and convenient it is to register the donation decision and that young adults have a vested interest in registering and discussing their donation decision because one day they or someone important to them may need an organ transplant or may need to make the decision to donate.

Unregistered young adults also indicated a lack of knowledge about the donation process in general, highlighting the importance of addressing the knowledge deficits identified in this study (and in other research ${ }^{12}$ ). In addition, young adults also indicated that uncertainty about how and when to raise the topic of donating organs would prevent them from discussing their donation decision. For this reason, providing practical suggestions about how and when to raise the topic as well as increasing young adults' confidence in their ability to discuss their donation decision may facilitate decision discussion.

\section{Limitations}

Although this study has many strengths, such as the use of a theoretical framework to understand young Australian adults' organ donation decisions, results should be interpreted in light of the limitations of the study. Limitations included participant self-report and the sample of predominantly white, female students, limiting generalizability to young adults in the wider community (although in 2005 in Australia, the majority of donors were white and $56 \%$ were students $^{3}$ ). Future research should examine the organ donationrelated behaviors of a broader representation of young adults in the general community.

Another potential limitation may be the inclusion of participants who were not registered and participants who were undecided about their donation decision. Previous research' has suggested that there may be 3 distinct groupings: individuals who have registered their decision, have not registered their decision, and who are undecided about their decision. Although our study focused on those who had and had not registered a donation decision rather than considering the various reasons underlying why an individual may not be registered, future research could examine these 3 groups separately to establish if there are differences in behavioral, normative, and control beliefs about organ donation.

Finally, results of the study suggest that the decision-making processes about registering and discussing organ donation preferences are complex: not only do individuals have different beliefs about communicating their organ donation decision, but they may choose different methods of communicating their decision as well. For instance, some individuals may choose to register their decision but not to discuss it; others may choose to discuss their decision but not to register it or choose not to communicate their decision at all. This complexity in decision making raises a measurement issue for future research and suggests that to encourage both registration and discussion behaviors for those individuals who have only partially communicated their decision (eg, registered but not discussed), more targeted strategies for each group need to be considered.

\section{Conclusion}

Overall, this study highlights important knowledge deficits and belief-based differences between young Australian adults who have and have not registered and discussed their donation decision. Given the need to increase organ donation decision registration and decision discussion, our study provides important applied information that can be used in the formulation of strategies to encourage potential donors to register and discuss their donation decision with family or significant others, so that the donation wishes of these potential donors can be carried out.

\section{References}

1. Baughn D, Rodrigue JR, Cornell DL. Intention to register as organ donors: a survey of adolescents. Prog Transplant. 2006:16(3):260-267.

2. Australians Donate. National body says organ donation should be seen as community responsibility. http://www .organdonation .org.au. Accessed October 15, 2005.

3. Excell L, Wride P, Russ GR, eds. Australia and New Zealand Organ Donation Registry Report 2006. Adelaide, South Australia: Australia and New Zealand Organ Donation Registry; 2006.

4. Gabel H. Organ donor registers, Curr Opin Organ Transplant. 2006;11:187-193.

5. Mathew T. The Australian experience in organ donation: 2003. Ann Transplant. 2004:9(1):28-30.

6. Australasian Transplant Coordinators Association Incorporated. National Guidelines for Organ and Tissue Donation. 3rd ed. Sydney, Australia: Australasian Transplant Coordinators Association Inc; 2006.

7. Nolan BE, Spanos NP. Psychosocial variables associated with willingness to donate organs. Can Med Assoc J. 1989; 141(1):27-32. 
8. Reubsaet A, van den Borne B, Brug J, Pruyn J, van Hooff $\mathrm{H}$. Determinants of the intention of Dutch adolescents to register as organ donors. Soc Sci Med. 2001;53:383-392.

9. Sirois BC, Sears SF, Marhefka S. Do new drivers equal new donors? An examination of factors influencing organ donation attitudes and behaviors in adolescents. J Behav Med. 2005;28(2):201-212

10. Radecki CM, Jaccard J. Psychological aspects of organ donation: a critical review and synthesis of individual and next-of-kin donation decisions. Health Psychol. 1997;16(2):183-195.

11. Brug J, Van Vugt M, Van Den Borne B, Brouwers A, Van Hooff $\mathrm{H}$. Predictors of willingness to register as an organ donor among Dutch adolescents. Psychol Health. 2000; 15:357-368.

12. Horton RL, Horton PJ. Knowledge regarding organ donation: identifying and overcoming barriers to organ donation. Soc Sci Med. 1990;31(7):791-800.

13. Hessing DJ, Elffers H. Attitude toward death, fear of being declared dead too soon, and donation of organs after death. Omega. 1986-1987;17(2):115-126.

14. Parisi N, Katz I. Attitudes toward posthumous organ donation and commitment to donate. Health Psychol. 1986;5(6):565-580.
15. Breitkopf CR. Perceived consequences of communicating organ donation wishes: an analysis of beliefs about defending one's decision. Psychol Health. 2006;21(4):481-497.

16. Ajzen I. The theory of planned behavior. Organ Hum Decision Proc. 1991;50:179-211.

17. Ajzen I, Madden TJ. Prediction of goal-directed behavior: attitudes, intentions, and perceived behavioral control. J Exp Soc Psychol. 1986;22:453-474.

18. Armitage CJ, Conner M. Social cognitive determinants of blood donation. J Appl Soc Psychol. 2001;31(7):1431-1457.

19. Johnston KL, White KM. Beliefs underlying binge-drinking in young female students: a theory of planned behaviour perspective. Youth Studies Australia. 2004;23(2):22-30.

20. Australian Bureau of Statistics. 1269.0 - Standard Australian Classification of Countries (SACC), 1998 (Revision 2.03). Canberra, Australia: Australian Bureau of Statistics; 2007.

21. Medicare Australia. Australian Organ Donor Register. http://www.medicareaustralia.gov.au/yourhealth/our _services/aaodr.shtml. Accessed May 29, 2007.

22. Australian Organ Donor Register. Frequently-Asked Questions. http://www.medicareaustralia.gov.au/yourhealth/our_services /aodr/faqs.htm. Accessed July 16, 2007. 